\title{
Publisher's Note: Evaluation of Colorado Learning Attitudes about Science Survey [Phys. Rev. ST Phys. Educ. Res. 10, 020128 (2014)]
}

\author{
K. A. Douglas, M. S. Yale, D. E. Bennett, M. P. Haugan, and L. A. Bryan
}

(Received 1 December 2014; published 9 December 2014)

DOI: 10.1103/PhysRevSTPER.10.029901 PACS numbers: 01.40.Fk, 01.40.G-, 01.40.Di, 01.50.Kw, 99.10.Fg

This paper was published online on 19 November 2014 with the omission of Fig. 1 and its caption and with extraneous numbers in Table IV. The paper has been corrected online as of 5 December 2014. 